\title{
High ionic exchange capacity polyphenylsulfone (SPPSU) and polyethersulfone (SPES) cross-linked by annealing treatment: Thermal stability, hydration level and mechanical properties
}

\author{
M.L. Di Vona ${ }^{\mathrm{a}, *}$, E. Sgreccia ${ }^{\mathrm{a}, \mathrm{b}}$, M. Tamilvanan ${ }^{\mathrm{a}}$, M. Khadhraoui $^{\mathrm{b}}$, C. $_{\text {Chassigneux }}^{\mathrm{b}}$, P. Knauth $^{\mathrm{b}}$ \\ a Università di Roma Tor Vergata, Dip. Scienze Tecnologie Chimiche, Roma,Italy \\ b Université de Provence-CNRS: UMR 6264 Laboratoire Chimie Provence, Centre St Jérôme, Marseille, France
}

\section{A R T I C L E I N F O}

\section{Article history:}

Received 17 November 2009

Received in revised form 17 January 2010

Accepted 22 February 2010

Available online 1 March 2010

\section{Keywords:}

Polymer electrolyte

Aromatic polymer

Water uptake

Swelling

PEM fuel cells

\begin{abstract}
A B S T R A C T
Thermal stability, hydration and mechanical properties of thermally cross-linked sulfonated aromatic polymers (SAP) with high ionic exchange capacity (IEC) were measured and compared to untreated samples. The formation of cross-linking greatly stabilizes sulfonated polyphenylsulfone (SPPSU) in terms of thermal, mechanical, and hydrolytic degradation: it can resist in water even at a temperature of $145^{\circ} \mathrm{C}$ with improved mechanical properties, while TGA experiments demonstrate that SPPSU membranes are stable well above $200^{\circ} \mathrm{C}$. Sulfonated polyethersulfone (SPES) membranes show, instead, a hydrolytic instability.
\end{abstract}

(C) 2010 Elsevier B.V. All rights reserved.

\section{Introduction}

Polyphenylsulfone (PPSU) and polyethersulfone (PES) are fully aromatic high performance polymers known to be amorphous thermoplastic materials. Among the other amorphous thermoplastic polymers, especially PPSU presents superior properties like an excellent thermal stability, a high chemical resistance, exceptional toughness and impact resistance ideal for aerospace, automotive and medical applications. Furthermore, PPSU and PES are not expensive and readily available [1]. The aromatic structure can be functionalized and when ionomeric groups, like sulfonic acid, are inserted in the polymeric backbone, the macromolecule can be used as a polymer electrolyte membrane. Sulfonated polyphenylsulfone (SPPSU) and polyethersulfone (SPES) belong to the family of sulfonated aromatic polymers (SAP), well known compounds in the community of polymer electrolyte membrane fuel cells (PEMFCs) [2-8]. Famous exponents of this class are sulfonated polyetheretherketone (SPEEK), sulfonated polyetherketoneketone (SPEKK), and sulfonated polysulfone (SPSU).

Although in the past, they were regarded as possible alternative to perfluorinated membranes, like Nafion, both in direct methanol and hydrogen fuel cells, today there is a large scepticism regarding their utilization especially in $\mathrm{H}_{2}$ PEMFCs working at intermediate

\footnotetext{
* Corresponding author. Tel.: +39 0672594385; fax: +390672594328

E-mail address: divona@uniroma2.it (M.L. Di Vona).
}

temperature. The problems that affect this class of polymers seem, in fact, difficult to solve. The main drawback is that in SAPs the water-filled channels are narrow and tortuous with a low separation between hydrophilic and hydrophobic domains. The distance between adjacent sulfonic groups is consequently large and for this reason SAPs necessitate a higher IEC compared to perfluorinated membranes to attain the required conductivity [9-11]. Unfortunately, high IEC leads also to morphological instability and large swelling $[9,12]$. In our laboratory, we have followed two different approaches to obtain stable and long-life membranes: the synthesis of hybrid organic-inorganic networks [13-16] and the formation of covalent cross-linking bonds between the macromolecules $[17,18]$.

The formation of cross-links is a well-established technique to improve the performances of polymers, used in a variety of applications [19-21]. The main drawbacks of this technique are the presence of cross-linker molecules that are in general sensible to the severe conditions in a fuel cell and the elaborate or expensive procedures that make the entire process little competitive from an industrial point of view. A direct cross-linking reaction performed in situ during the casting procedure can be instead an interesting and promising methodology to obtain stable and long-life membranes.

In a previous paper, we have illustrated the possibility to perform cross-linking reactions through sulfonic groups directly by thermal treatment of SPEEK membranes [22]. This reaction can be applied to the whole family of SAP and in this work we present the first data obtained for SPPSU and SPES. 
Contrary to the better-known polysulfones, SPPSU and SPES have not received much attention and not many papers exist in the literature regarding their utilization in PEMFCs [23-31]. Polyphenylsulfone presents some peculiarities with respect to the other members of the SAP family. The direct linkage between aromatic moieties makes the structure more rigid, but at the same time it leads to the presence of two activated phenyl rings for the electrophilic aromatic substitution reaction. Consequently, it is easily possible to introduce two sulfonic acid groups per repeat unit, which leads to a high ionic exchange capacity $($ IEC $=3.57 \mathrm{meq} / \mathrm{g}$ ) [32]. A part of sulfonic acid groups can be sacrificed to perform further functionalization, such as cross-linking, without a sensible loss in electrochemical performances. An elevated IEC is in fact an essential requisite for SAPs to obtain suitable proton conductivity for PEM fuel cells [33].

Instead, PES is difficult to sulfonate due to the electron withdrawing effect of the sulfone linkages that deactivate the adjacent aromatic rings for electrophilic substitution and its sulfonation required stronger reagents or/and longer time [34,35]; under these conditions, up to two sulfonic groups can however be inserted per repeat unit. SPES is more hydrophilic than other SAP membranes due to its short and polar repeat unit. Its low molecular weight $(312 \mathrm{~g} / \mathrm{mol})$ leads to high IEC values even for a relatively low degree of sulfonation ( $\mathrm{DS}=1$ corresponds to $3.2 \mathrm{meq} / \mathrm{g}$ ) and it reaches conductivity values similar to highly sulfonated SPEEK. However, SPES membranes with suitable DS dissolve easily in water.

In this contribution, we examine if the formation of covalent bonds among macromolecular chains can stabilize the polymer microstructure and can make them suitable for further investigations. We present experiments on thermal stability, hydration and mechanical properties of thermally cross-linked SPPSU and SPES membranes, which are compared to untreated samples.

\section{Experimental}

\subsection{Synthesis}

\subsubsection{SPPSU: sulfonation of PPSU}

Polyphenylsulfone (Solvay, PPSU, MW $=46173 \mathrm{~g} / \mathrm{mol}, 20 \mathrm{~g}$, 50 meq) was dissolved in $\mathrm{H}_{2} \mathrm{SO}_{4}$ (Carlo Erba 96\%, $1 \mathrm{~L}$ ) and stirred at $50^{\circ} \mathrm{C}$ for 5 days. The solution was poured in a large excess of ice-cold water under continuous stirring, obtaining a white precipitate. After standing overnight, the precipitate was filtered and washed several times with cold water to neutral $\mathrm{pH}$. The sulfonated polymer (SPPSU) was then dried under vacuum for 4-6 h at room temperature. The degree of sulfonation (DS) was evaluated both by elemental analysis and by titration. Both methods gave according results, indicating a DS $=2$ corresponding to an IEC of $3.57 \mathrm{meq} / \mathrm{g}$.

\subsubsection{SPES: sulfonation of PES}

Polyethersulfone (Victrex, PES, MW $=67080 \mathrm{~g} / \mathrm{mol}, 10 \mathrm{~g}$, $32 \mathrm{meq}$ ) was dissolved at room temperature with chlorosulfonic acid (Sigma Aldrich 99\%, $50 \mathrm{ml}$ ) and stirred at RT for $20 \mathrm{~h}$. The solution was then poured in $150 \mathrm{ml}$ of sulfuric acid (Carlo Erba 96\%) and kept under stirring at RT for $2 \mathrm{~h}$. It was then precipitated with ice-cold water while stirring. After standing overnight, the precipitate was washed with ice-cold water until $\mathrm{pH}$ value of 5-6 and dried at $80^{\circ} \mathrm{C}$ for $20 \mathrm{~h}$ under vacuum [36]. The degree of sulfonation, evaluated by titration and NMR, was DS $=0.83$ corresponding to an IEC of $2.78 \mathrm{meq} / \mathrm{g}$.

\subsection{Preparation of membranes}

The procedure for membrane preparation using dimethylsulfoxide (DMSO) as solvent casting was previously described [21]. In a typical experiment $\sim 250 \mathrm{mg}$ sample was dissolved in $30 \mathrm{~mL}$ of solvent. The resulting mixture was stirred for $4 \mathrm{~h}$, evaporated to $5 \mathrm{~mL}$, cast onto a Petri dish, and heated to dryness for $16 \mathrm{~h}$ at $120^{\circ} \mathrm{C}$. After being allowed to cool to room temperature, the resulting membranes were peeled off and heated under dynamic vacuum for $24 \mathrm{~h}$ at $80^{\circ} \mathrm{C}$ for solvent removal (called "untreated samples" in the following discussion). However, a small amount of DMSO remained in the membranes after this step [21].

In the case of highly sulfonated PES, the membrane casting was more difficult, because the samples were very hydrophilic and did not separate easily from the Petri dish. The Petri dish was treated with silicon oil to reduce the membrane adhesion.

Subsequent thermal treatments of SPPSU membranes were performed at $170^{\circ} \mathrm{C}$ for 24,48 or $64 \mathrm{~h}$ (IEC 2.35 , degree of cross-linking per repeat unit was 0.8 ) and for SPES at 160 or $170^{\circ} \mathrm{C}$ for $64 \mathrm{~h}$ (called "treated samples" in the following discussion).

\subsection{Measurements}

\subsubsection{Structural characterization}

FT-IR spectra of membrane samples heated to different temperatures were collected in transmission mode in the range of $4000-400 \mathrm{~cm}^{-1}$ (32 scans, $2 \mathrm{~cm}^{-1}$ resolution) with a Bruker Equinox 55. The membrane thickness was ca. $60 \mu \mathrm{m}$ in all cases. A background spectrum was run and sample spectra were normalized against the background spectrum.

${ }^{1} \mathrm{H}$ nuclear magnetic resonance spectra were recorded in $\mathrm{d}_{6^{-}}$ DMSO with a Bruker Avance 400 spectrometer operating at 400.13 MHz. Chemical shifts (ppm) are referenced to tetramethylsilane (TMS).

The morphology and the roughness of the membranes were monitored by atomic force microscopy (AFM) with a PARK AUTOPROB Cp. The AFM images were obtained with scans of 80, 20 and $5 \mu \mathrm{m}$ using MPP31 probes (Silicon Cantilever).

\subsubsection{Mechanical properties}

Stress-strain tests. The mechanical properties of SPPSU were investigated using an ADAMEL Lhomargy DY30 test machine at room temperature at a constant crosshead speed of $5 \mathrm{~mm} / \mathrm{min}$ with aluminium sample holders as described in Ref. [37]. Prior to the measurements, the polymer samples were stabilized at ambient temperature and humidity, which was $(50 \pm 10) \%$ RH. The measurement time was below 5 min.

\subsubsection{Thermal behaviour}

The thermal degradation of polymer membranes was investigated by high resolution thermogravimetric analysis (TGA Q500, TA Instruments), performed between 25 and $600^{\circ} \mathrm{C}$ with a maximum heating rate of $5 \mathrm{~K} \mathrm{~min}^{-1}$ under air flux in platinum sample holders.

\subsubsection{Water uptake measurements}

Water uptake was measured by two complementary experiments. (i) By full immersion in deionized water at temperatures between 25 and $145^{\circ} \mathrm{C}$ : polymer samples were weighed before and after immersion times between $1 \mathrm{~h}$ and 6 days (hydrothermal treatments above $100^{\circ} \mathrm{C}$ were performed in hermetically closed Teflon vessels) [38]; (ii) by equilibration with water vapour at $25^{\circ} \mathrm{C}$ under $0-95 \% \mathrm{RH}$ [37]. The water sorption isotherms were recorded using a TA5000 thermogravimetric analyzer. RH was modified in 5 or $10 \%$ steps and the water uptake recorded at each step for $2 \mathrm{~h}$ at 25 and $50{ }^{\circ} \mathrm{C}$. Prior to all experiments, the membranes were first dried in situ for $3 \mathrm{~h}$ at $80^{\circ} \mathrm{C}$ under $0 \% \mathrm{RH}$. 
<smiles>Cc1ccc(S(=O)(=O)c2ccc(Oc3ccc(C45CCC(CC4)C(O)C5OS(=O)(=O)O)cc3)cc2)cc1</smiles>

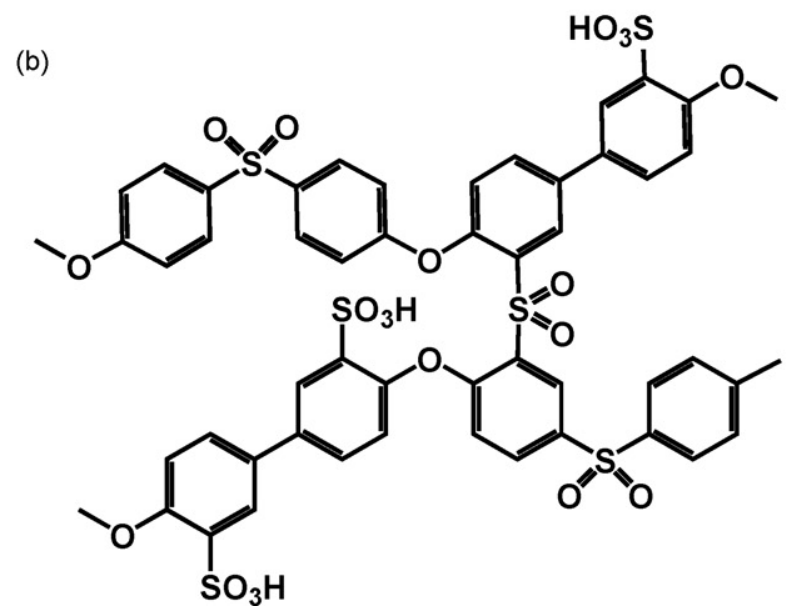<smiles>Cc1ccc(S(=O)(=O)c2ccc(Oc3ccc(CC(C)C)cc3)cc2)cc1</smiles>

SPES DS $=0.83$

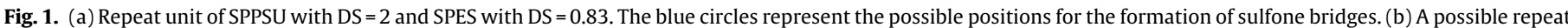

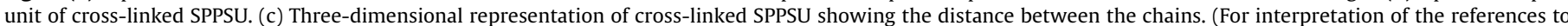
color in this figure legend, the reader is referred to the web version of the article.)

\section{Results and discussion}

\subsection{Structure and microstructure}

Fig. 1 shows the repeat units of SPPSU (before and after the cross-linking) and SPES. The reaction pathways for cross-linked SPEEK are discussed in Ref. [21]. They involve electrophilic aromatic substitution over $\mathrm{SO}_{2}{ }^{+}$electrophilic intermediates generated during solvothermal treatment of casted membranes. The charge separation is facilitated by the presence of the high dielectric constant solvent DMSO in the membranes. The formation of cross-links between macromolecular chains during solvothermal treatment in presence of DMSO is common to many SAP.

Fig. 2 shows FT-IR analysis of an untreated SPPSU sample and a sample heated at $170^{\circ} \mathrm{C}$ for $64 \mathrm{~h}$. Both spectra are dominated by PPSU infrared bands, in particular it is possible to observe signals at 1320 and $1150 \mathrm{~cm}^{-1}$ due to $S=0$ stretching (asymmetric and symmetric respectively) together with band at 1105 and $1084 \mathrm{~cm}^{-1}(v \mathrm{C}-\mathrm{S})$. The signal at $1170 \mathrm{~cm}^{-1}$ is due to two contributions: $-\mathrm{SO}_{3}$ groups and ring modes of 1:2-substituted benzene, while the absorptions at $1020 \mathrm{~cm}^{-1}\left(v_{\text {sym }}-\mathrm{SO}_{3} \mathrm{H}\right)$, and $965 \mathrm{~cm}^{-1}$ $\left(\delta-\mathrm{SO}_{3} \mathrm{H}\right)$ are due to aromatic sulfonic groups [18]. Considering that cross-linking leads to the formation of sulfone bonds, already present in the backbone of the polymer, no appreciable difference between the two spectra can be expected. However, subtraction of the normalized spectrum of untreated SPPSU from that of $170^{\circ} \mathrm{C}$ treated SPPSU (Fig. 2c) reveals the presence of supplementary S-O stretching vibrations at $1155 \mathrm{~cm}^{-1}$, due to $\mathrm{PhSO}_{2} \mathrm{Ph}$ generated in the cross-linking reaction. Signals due to $1: 2: 4$-substituted phenyl rings are present at $1080 \mathrm{~cm}^{-1}$. It is also possible to observe bands of aromatic sulfone moieties at $1210 \mathrm{~cm}^{-1}$ (shoulder) and $1065 \mathrm{~cm}^{-1}$ (tail) [39]. Intensity variation of signals due to aromatic sulfonic groups ( 1180 and $1020 \mathrm{~cm}^{-1}$ ) is also observed indicating a reduced amount of acidic groups in the treated SPPSU.

${ }^{1} \mathrm{H}$ NMR spectra of PES and SPES in DMSO are shown in Fig. 3. The presence of a sulfonic acid group causes a significant downfield shift of the hydrogen located in $o$-position at the aromatic ring. From the spectrum, one can calculate the degree of sulfonation, according to Ref. [31] (DS=0.83); furthermore, it is possible to exclude the degradation of the polymer during sulfonation.

Fig. 4 presents AFM images of sulfonated PPSU membranes before and after thermal treatment. The membrane surfaces are very smooth; the RMS value is about $2 \mathrm{~nm}$ and decreases slightly after thermal treatment.

\subsection{Properties}

The maximum working temperature of SAP membranes is currently limited to $80-90^{\circ} \mathrm{C}$, which is a strong limitation for use in PEMFC. Working temperatures in the range of $120-130^{\circ} \mathrm{C}$ are highly desirable [40] and all the physical and chemical modifications able to increase thermal stability, durability, performance and cost are expected to have positive effects on the development of PEMFC systems. Furthermore, the behaviour of thinner membranes is less sensitive to temperature changes, which may be an important aspect for the working characteristics of the fuel cell. However, prerequisite for use of thin membranes is high performance mechanical properties of the ionomer. Analysis of the 

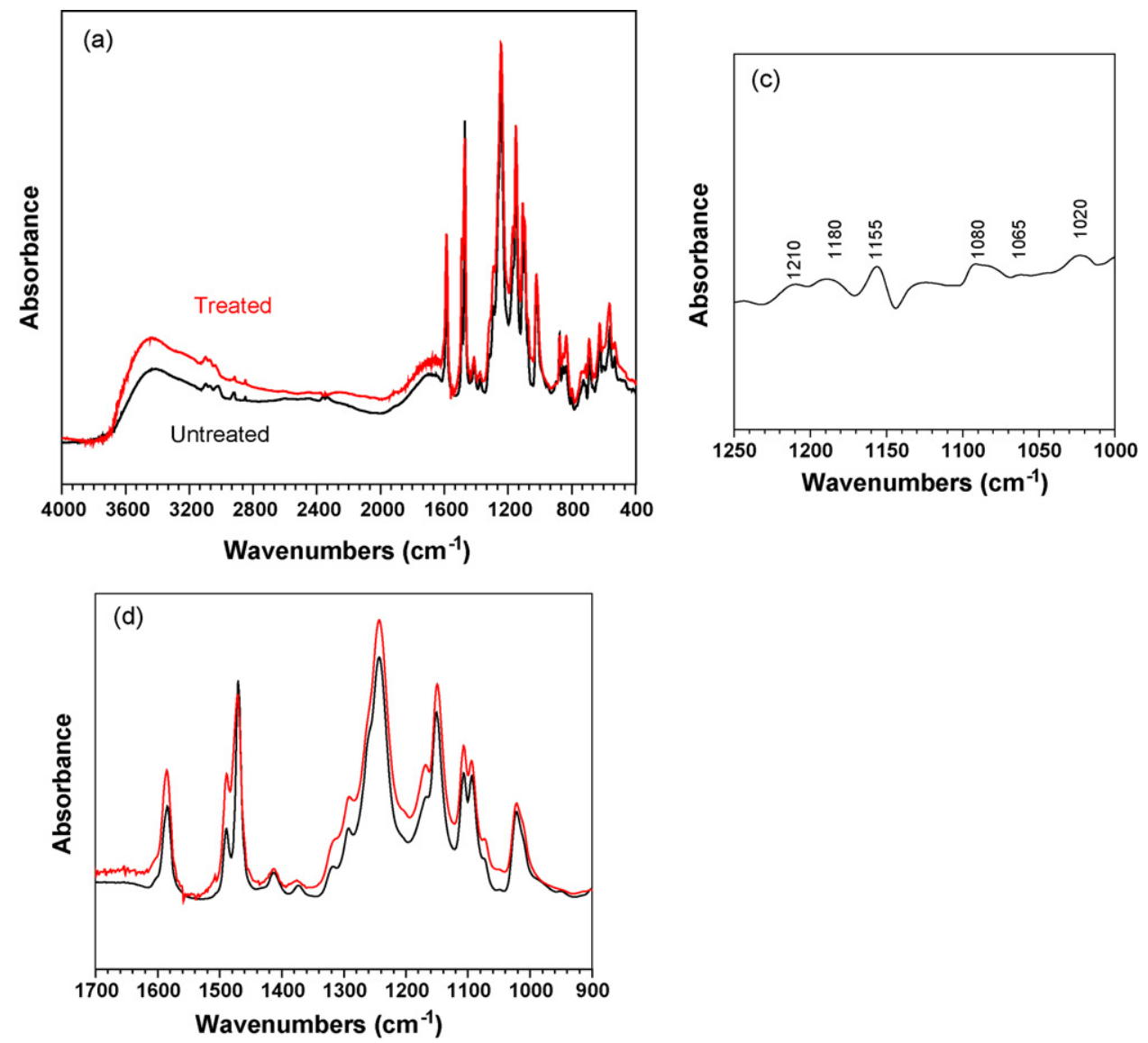

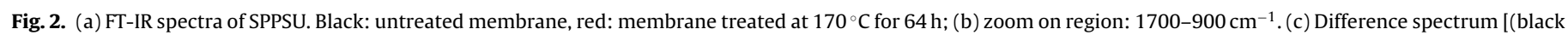
line) - 1(red line)].

(a)

$$
H_{A, A^{\prime}} \quad H_{B, B}
$$
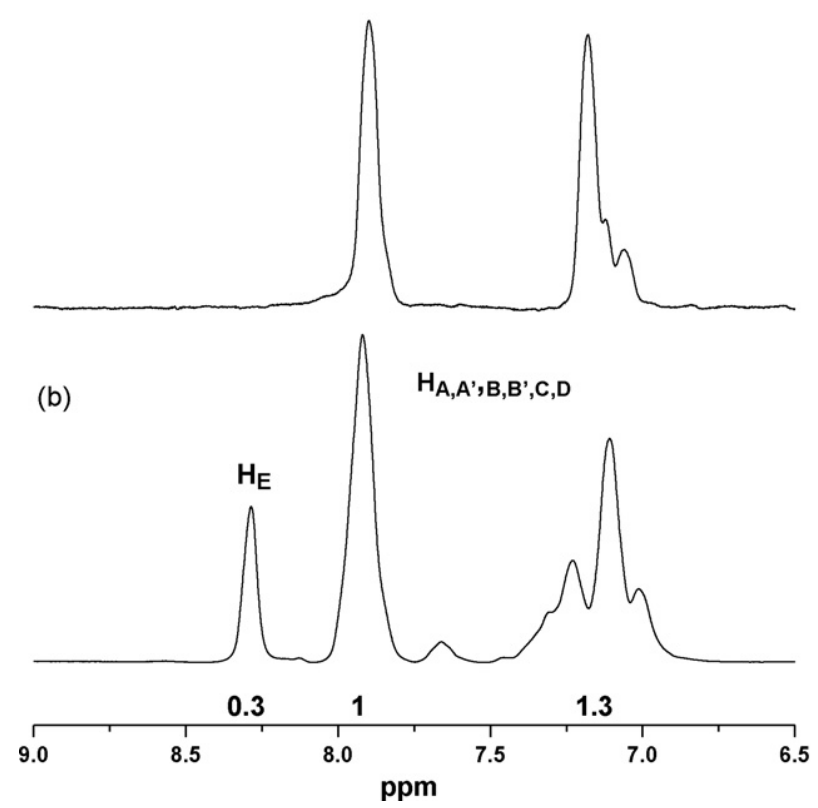<smiles>COc1ccc(S(=O)(=O)c2ccc(C)cc2)cc1S(=O)(=O)O</smiles>

$\mathrm{DS} /(8-2 \mathrm{DS})=\mathrm{AH}_{\mathrm{E}} / \Sigma \mathrm{AH}_{\mathrm{A}, \mathrm{A}^{\prime}, \mathrm{B}, \mathrm{B}^{\prime}, \mathrm{C}, \mathrm{D}}$

Fig. 3. ${ }^{1} \mathrm{H}$ NMR of (a) unsulfonated PES and (b) sulfonated PES in $\mathrm{d}_{6}$-DMSO. 
(a)

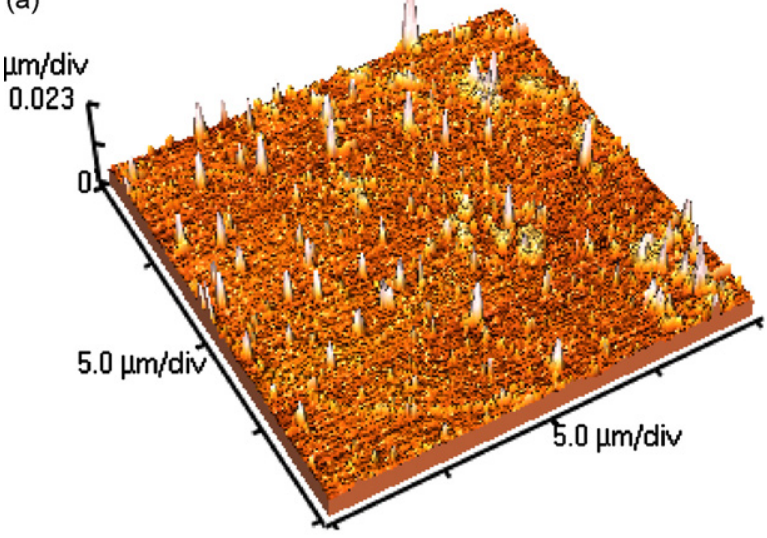

(b)

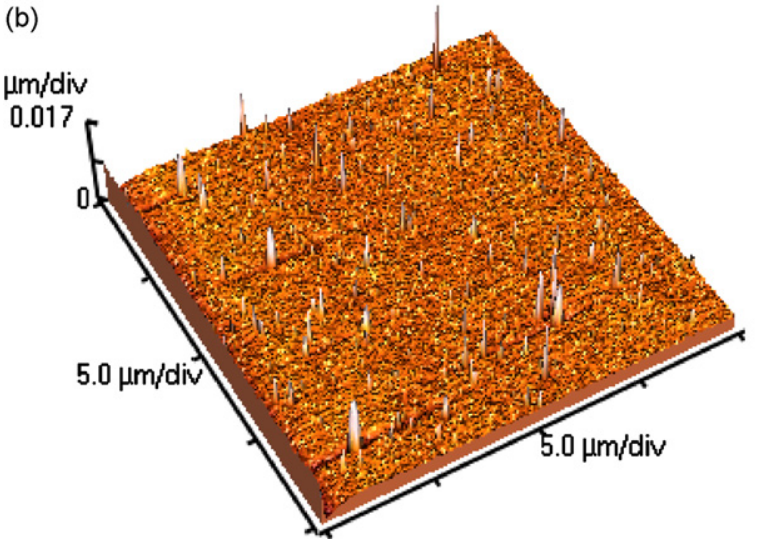

Fig. 4. AFM images of S-PPSU membranes (a) untreated and (b) after heat treatment at $170^{\circ} \mathrm{C}$ for $64 \mathrm{~h}$.

mechanical properties is thus an important element for membrane development.

The new cross-linked SAP membranes are very promising from a degradation point of view. In fact, among the causes that lead to the degradation of SAP membranes, we can individuate three important reasons: (a) thermal degradation; (b) mechanical degradation; (c) hydrolytic degradation. These factors will now be discussed, based on our results.

\subsubsection{Thermal degradation}

Fig. 5 shows the thermogravimetric analysis of untreated SPPSU and SPPSU annealed at $170^{\circ} \mathrm{C}$ for 48 or $64 \mathrm{~h}$. The first mass loss above $150^{\circ} \mathrm{C}$ is observed only for untreated samples: it corresponds to loss of residual solvent DMSO. The mass loss above $200^{\circ} \mathrm{C}$ is due to the removal of sulfonic acid groups; heat-treated samples present a distinctly lower mass loss, because a part of the sulfonic acid groups has reacted previously during thermal treatment to form sulfone cross-links. There is also a large difference between the two treated samples, showing that many more cross-links were formed after $64 \mathrm{~h}$ than after $48 \mathrm{~h}$ at $170^{\circ} \mathrm{C}$. This might indicate a time of latency for the cross-linking reaction. Furthermore, the removal of sulfonic acid groups due to cross-linking increases the temperature of pyrolysis of the polymer up to about $450^{\circ} \mathrm{C}$; however, there seems to be an optimum concentration of sulfonic acid groups above which the pyrolysis temperature decreases again.

Fig. 6 shows TGA of untreated SPPSU up to $300^{\circ} \mathrm{C}$ (a: mass loss, b: derivative curve). The first mass loss above $150^{\circ} \mathrm{C}$ corresponds to loss of DMSO, the second to loss of sulfonic acid groups, as discussed before. The second loss is clearly different for pretreated and untreated samples: for treated samples the derivative curve has a Gaussian shape, whereas for untreated ones the loss of sulfonic acid

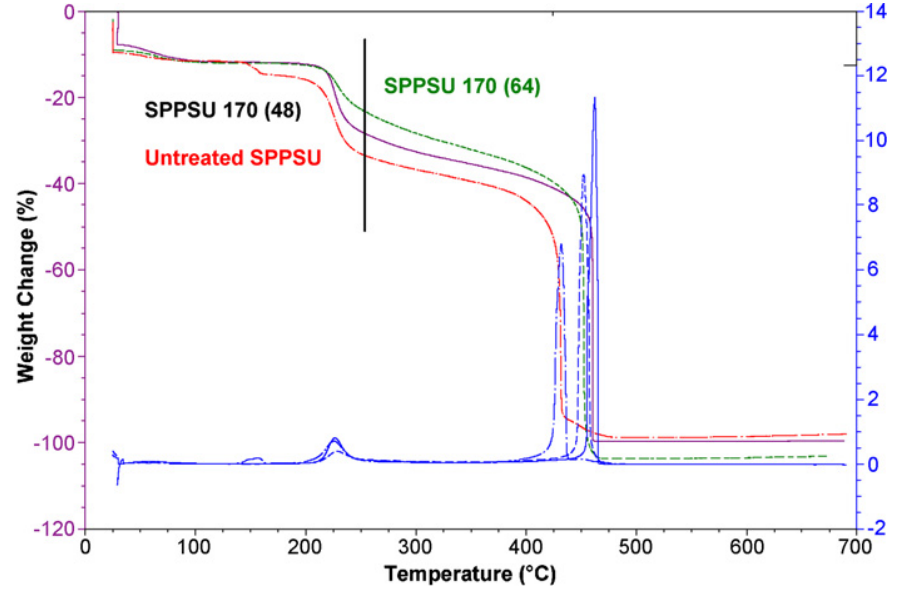

Fig. 5. Thermogravimetric analysis of untreated SPPSU (red line), SPPSU treated at $170{ }^{\circ} \mathrm{C}$ for $48 \mathrm{~h}$ (black line) and SPPSU treated at $170{ }^{\circ} \mathrm{C}$ for $64 \mathrm{~h}$ (green line). The blue curves represent the derivative signal. (For interpretation of the references to color in this figure legend, the reader is referred to the web version of the article.)

groups starts earlier and the curve is asymmetrical, indicating "in situ" cross-linking.

Fig. 6c shows a more elaborate TGA experiment: curve 1 is the mass loss until $300^{\circ} \mathrm{C}$. The insert represents a zoom of the curve 1 . After cooling the same sample to $50^{\circ} \mathrm{C}$, a second run (heating from 50 to $700^{\circ} \mathrm{C}$, curve 2 ) does not show a mass loss before $450^{\circ} \mathrm{C}$. All these measurements confirm that the cross-linking reaction leads to loss of sulfonic acid groups and this is fully consistent with the IR analysis and previous results reported in [21].

Fig. 7 presents TGA of SPES treated at $160^{\circ} \mathrm{C}$ for $64 \mathrm{~h}$. Features similar to SPPSU can be observed for SPES with a slightly higher temperature of loss of sulfonic acid groups, which might be due to hydrogen bonding between the near sulfonic acid moieties. The final pyrolysis temperature is slightly below that for SPPSU.

Altogether, TGA experiments demonstrate that SPPSU and SPES membranes are stable well above $200^{\circ} \mathrm{C}$. Usual SAP membranes stop working at high temperatures due to the low glass transition temperatures of the polymers. Dynamical mechanical analysis results on SPEEK and SPPSU showed that the thermal treatment increases the glass transition temperature well above $200^{\circ} \mathrm{C}$ for SPPSU [41]. Although the long-time thermal stability of membranes cannot be assessed from TGA data alone, these results are still very encouraging for the future use of these membranes in intermediate temperature PEM fuel cells.

\subsubsection{Mechanical degradation}

Typical mechanical traction experiments (stress-strain curve) of SPPSU (Fig. 8) permit the calculation of elastic modulus $E$, tensile strength MPa and elongation at rupture. The very high elastic modulus, relatively high tensile strength and low elongation at rupture of SPPSU are consistent with a polymer well below its glass transition temperature $\left(t_{\mathrm{g}}>200^{\circ} \mathrm{C}\right)$. In the case of SPES it was impossible to obtain sufficiently large samples for the mechanical tests, because they were damaged on separation from the Petri dish.

During fuel cell operation, the dimensional changes due to membrane swelling in different humidification conditions and the exothermic combustion of the fuel cause perforations, fractures and pinholes. These defects further increase gas crossover and therefore a critical sequence of increasing gas crossover and pinhole formation is quickly established [42]. We observe here that when SAP are thermally treated in selected conditions the mechanical properties are greatly improved. This effect was previously observed for SPEEK and attributed in part to the presence of cross-linking and in part to irreversible changes of conformation [50]. Furthermore, treated 

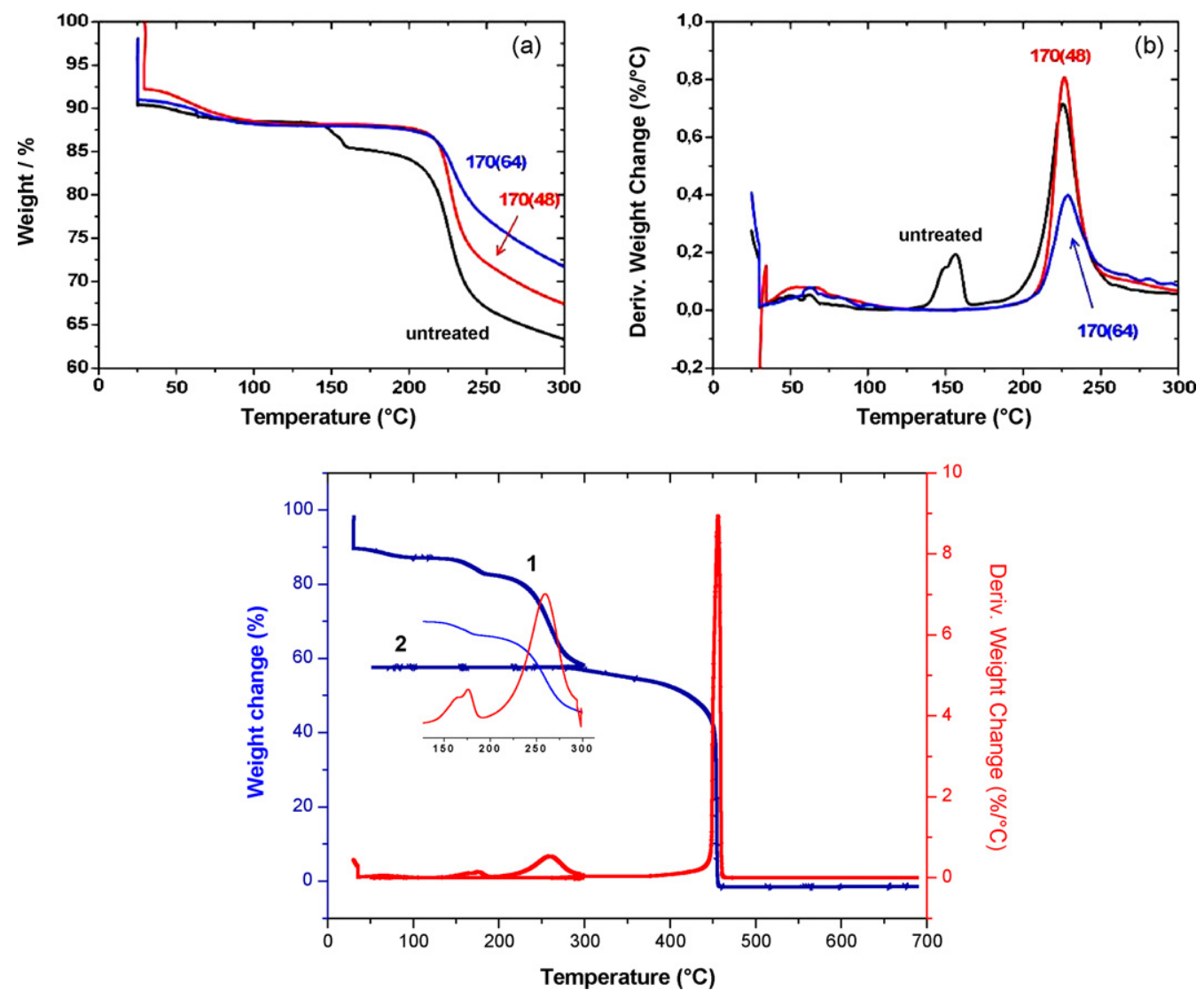

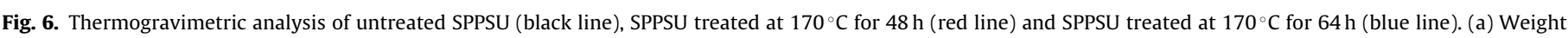

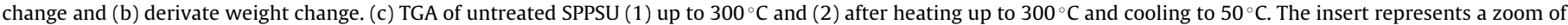
the curve 1. (For interpretation of the references to color in this figure legend, the reader is referred to the web version of the article.)

membranes also show a minor pinhole distribution linked with the treatment performed. In fact, the AFM images made did not reveal any pinholes.

\subsubsection{Hydrolytic degradation}

The water uptake kinetics of SPPSU in liquid water at various temperatures is shown in Fig. 9. SPES, instead, dissolves in water at room temperature after 24 h due to the still very high hydrophilicity of the polymer. Attempts to improve the water uptake behaviour by formation of a hybrid organic-inorganic membrane are currently in progress.

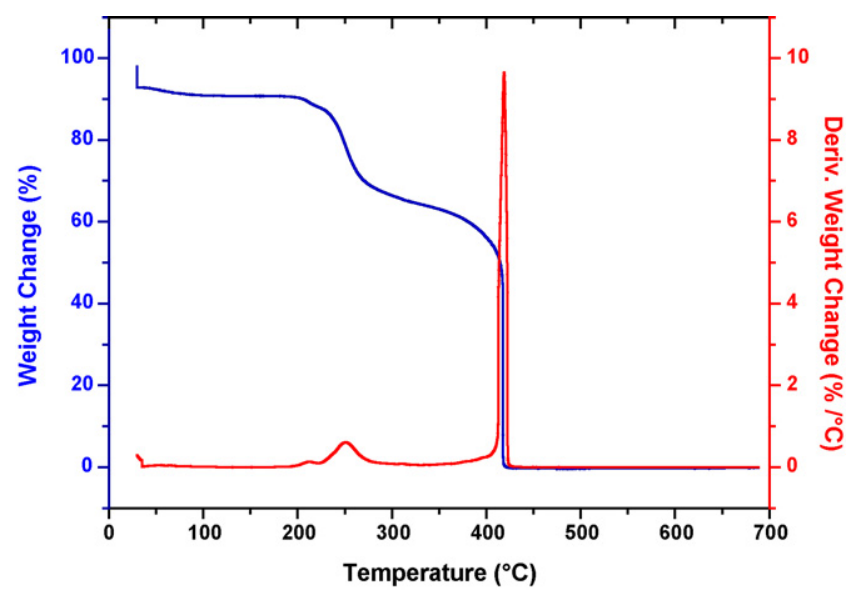

Fig. 7. Thermogravimetric analysis of SPES membrane treated at $160^{\circ} \mathrm{C}$ for $64 \mathrm{~h}$.
Fig. 10 presents the water uptake kinetics of SPPSU. Fig. 11 shows the water uptake isotherm of SPPSU and SPES membranes in water vapour at $50^{\circ} \mathrm{C}$. The water uptake above $80 \% \mathrm{RH}$ is impossible to determine for SPES, which swells and dissolves. It is evident that the heated SPPSU membranes have a distinctly lower water uptake, which is consistent with the data obtained with liquid water. The

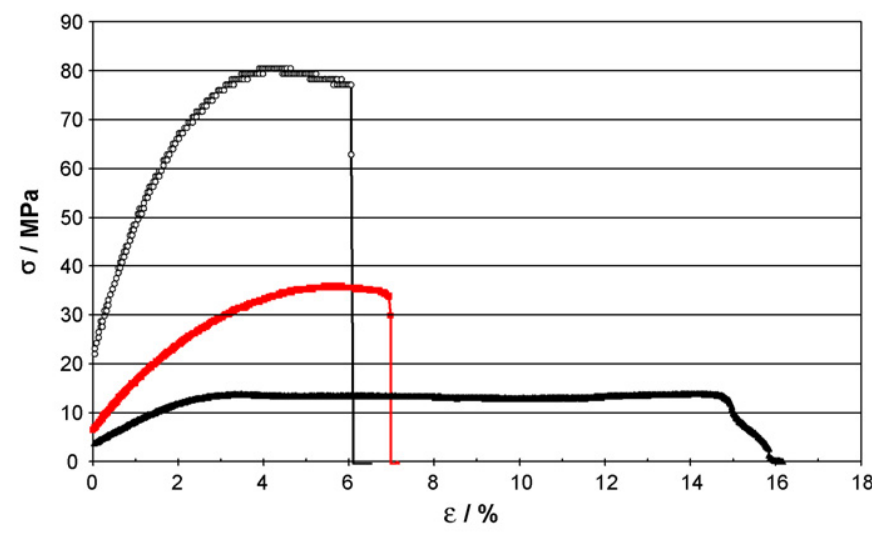

\begin{tabular}{|l|l|l|l|}
\hline \multicolumn{1}{|c|}{$\begin{array}{c}\text { SPPSU } \\
\mathrm{T}(\mathrm{t})\end{array}$} & \multicolumn{1}{c|}{$\begin{array}{c}\text { Elastic } \\
\text { modulus } \\
E(\mathrm{MPa})\end{array}$} & $\begin{array}{c}\text { Tensile } \\
\text { strength } \\
\sigma_{\max }(\mathrm{MPa})\end{array}$ & $\begin{array}{c}\text { Elongation at } \\
\text { rupture } \\
\varepsilon_{r}(\%)\end{array}$ \\
\hline Untreated & $540 \pm 130$ & $13 \pm 4$ & $17 \pm 6$ \\
\hline $170(48)$ & $850 \pm 200$ & $30 \pm 10$ & $6 \pm 1$ \\
\hline $170(64)$ & $2950 \pm 300$ & $80 \pm 3$ & $7 \pm 3$ \\
\hline
\end{tabular}

Fig. 8. Typical nominal stress-strain curve for SPPSU membranes (a) untreated, (b) treated at $170^{\circ} \mathrm{C}$ for $48 \mathrm{~h}$ and (c) treated at $170^{\circ} \mathrm{C}$ for $64 \mathrm{~h}$. 


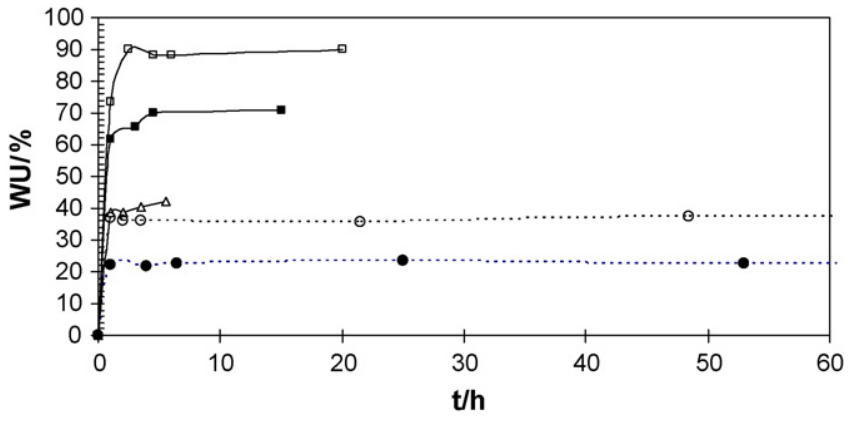

Fig. 9. Water uptake kinetics by immersion in liquid water of a SPPSU membrane

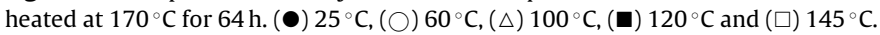

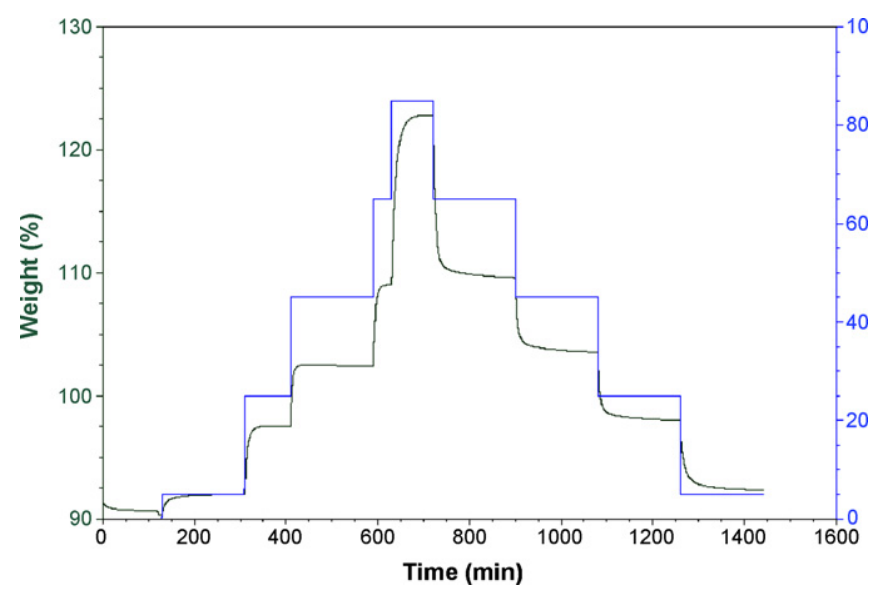

Fig. 10. Typical water uptake kinetics of untreated SPPSU membranes.

water uptake remains very reasonable even in liquid water at temperatures as high as $145^{\circ} \mathrm{C}$. Swelling phenomena are very reduced after heat treatment. The higher mechanical strength of thermally treated SPPSU membranes due to irreversible changes of conformation and covalent cross-linking between macromolecular chains increases the resistance against penetration of water. The crosslinks are stable against hydrolysis, as can be deduced from the following experiment: very remarkably, once cross-linked membranes are immersed in water and water is removed by drying over $\mathrm{P}_{2} \mathrm{O}_{5}$, the water uptake remains identical after renewed immersion in water. The kinetic analysis (Fig. 9) shows that the sorption of water is a fast process. Alberti et al. [38] discussed the decrease of water uptake rate with the temperature in Nafion as result of two distinct processes, the first very fast and the second very slow. The fast process was attributed to the equilibration necessary for the water diffusion within the thin membrane, while the slow process was associated with a modification of the polymer conformation

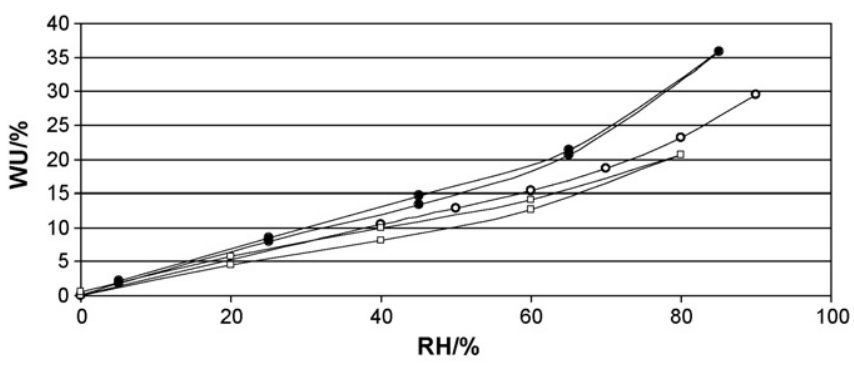

Fig. 11. Water sorption/desorption isotherms at $50^{\circ} \mathrm{C}$ of SPPSU membranes ( untreated, $(\bigcirc)$ heated $170^{\circ} \mathrm{C}$ for $64 \mathrm{~h}$ and SPES membrane treated at $160^{\circ} \mathrm{C}$ for $64 \mathrm{~h}$ $(\square)$. with the temperature. Similar mechanisms seem to be applicable also to SAP.

\section{Conclusion}

The new method for introducing a certain degree of covalent bonds between adjacent polymeric chains by heat treatment of cast membranes is really economic, since the cross-linking reaction can be performed directly after membrane casting. Due to its simplicity, it is furthermore very suitable for industrial preparation of cross-linked membranes, because the procedure can be easily upscaled. However, a delicate balance still exists between hydrophilic character of membranes and their properties. For example, highly sulfonated SPES membranes are difficult to separate from the casting substrate. All in all, cross-linking of highly sulfonated SAP by thermal treatment, especially for SPPSU, opens new horizons for use as PEM fuel cell membranes. In the case of SPES the formation of an organic-inorganic hybrid in the macromolecular chain seems very promising to reduce the hydrophilicity of the polymer.

\section{Acknowledgments}

The authors thank the Franco-Italian University for a thesis grant (Vinci program 2006) and the Italian Ministry of University and Research for financial support (PRIN 2007 project).

\section{References}

[1] C.D. Craver, C.E. Carraher, Applied Polymer Science 21st Century, Elsevier, Amsterdam [Netherlands]; New York, 2000.

[2] R.W. Kopitzke, C.A. Linkous, H.R. Anderson, G.L. Nelson, Conductivity and wate uptake of aromatic-based proton exchange membrane electrolytes, J. Electrochem. Soc. 147 (2000) 1677-1681.

[3] K. Miyatake, Y. Chikashige, E. Higuchi, M. Watanabe, Tuned polymer electrolyte membranes based on aromatic polyethers for fuel cell applications, J. Am. Chem. Soc. 129 (2007) 3879-3887.

[4] A.L. Rusanov, D. Likhatchev, P.V. Kostoglodov, K. Mullen, M. Klapper, Protonexchanging electrolyte membranes based on aromatic condensation polymers, in: Inorganic Polymeric Nanocomposites and Membranes, Springer, 2005, pp. 83-134.

[5] M.L. Einsla, Y.S. Kim, M. Hawley, H.S. Lee, J.E. McGrath, B.J. Liu, M.D. Guiver, B.S. Pivovar, Toward improved conductivity of sulfonated aromatic proton exchange membranes at low relative humidity, Chem. Mater. 20 (2008) 5636-5642.

[6] B. Smitha, S. Sridhar, A.A. Khan, Solid polymer electrolyte membranes for fue cell applications - a review, J. Membr. Sci. 259 (2005) 10-26.

[7] G. Alberti, M. Casciola, L. Massinelli, B. Bauer, Polymeric proton conducting membranes for medium temperature fuel cells (110-160 degrees C), J. Membr. Sci. 185 (2001) 73-81.

[8] R. Devanathan, Recent developments in proton exchange membranes for fuel cells, Energy Environ. Sci. 1 (2008) 101-119.

[9] K.D. Kreuer, On the development of proton conducting polymer membranes for hydrogen and methanol fuel cells, J. Membr. Sci. 185 (2001) 29-39.

[10] Y.D. Premchand, M.L. Di Vona, P. Knauth, Proton conducting nanocomposite and hybrid polymers, in: Nanocomposites: Ionic Conducting Materials and Structural Spectroscopies, Springer, 2008.

[11] B. Liu, D.S. Kim, M.D. Guiver, Y.S. Kim, B.S. Pivovar, Sulfonated poly(aryl ether)type polymers as proton exchange membranes: synthesis and performance, in Membranes for Energy Conversion, Wiley, 2008, pp. 1-45.

[12] P.X. Xing, G.P. Robertson, M.D. Guiver, S.D. Mikhailenko, K.P. Wang, S Kaliaguine, Synthesis and characterization of sulfonated poly(ether ether ketone) for proton exchange membranes, J. Membr. Sci. 229 (2004) 95-106.

[13] M.L. Di Vona, A. D’Epifanio, D. Marani, M. Trombetta, E. Traversa, S. Lic occia, SPEEK/PPSU-based organic-inorganic membranes: proton conducting electrolytes in anhydrous and wet environments, J. Membr. Sci. 279 (2006) $186-191$.

[14] M.L. Di Vona, D. Marani, A. D’Epifanio, S. Licoccia, I. Beurroies, R. Denoyel, P. Knauth, Hybrid materials for polymer electrolyte membrane fuel cells: water uptake, mechanical and transport properties, J. Membr. Sci. 304 (2007) 76-81.

[15] M.L. Di Vona, E. Sgreccia, S. Licoccia, M. Khadhraoui, R. Denoyel, P. Knauth, Composite proton-conducting hybrid polymers: water sorption isotherms and mechanical properties of blends of sulfonated PEEK and substituted PPSU Chem. Mater. 20 (2008) 4327-4334.

[16] E. Sgreccia, M. Khadhraoui, C. de Bonis, S. Licoccia, M.L. Di Vona, P. Knauth, Mechanical properties of hybrid proton conducting polymer blends based on sulfonated polyetheretherketones, J. Power Sources 178 (2008) 667-670. 
[17] D. Marani, M.L. Di Vona, E. Traversa, S. Licoccia, I. Beurroies, P.L. Llewellyn, P. Knauth, Thermal stability and thermodynamic properties of hybrid protonconducting polyaryl etherketones, J. Phys. Chem. B 110 (2006) 15817-15823.

[18] M.L. Di Vona, D. Marani, C. D’Ottavi, M. Trombetta, E. Traversa, I. Beurroies, P. Knauth, S. Licoccia, A simple new route to covalent organic/inorganic hybrid proton exchange polymeric membranes, Chem. Mater. 18 (2006) 69-75.

[19] J. Kerres, W. Cui, R. Disson, W. Neubrand, Development and characterization of crosslinked ionomer membranes based upon sulfinated and sulfonated PSU - crosslinked PSU blend membranes by disproportionation of sulfinic acid groups, J. Membr. Sci. 139 (1998), 211-225.q.

[20] J.A. Kerres, Blended and cross-linked ionomer membranes for application in membrane fuel cells, Fuel Cells 5 (2005) 230-247.

[21] D. Wu, L. Wu, J.-J. Woo, S.-H. Yun, S.-J. Seo, T. Xu, S.-H. Moon, A simple heat treatment to prepare covalently crosslinked membranes from sulfonated poly(2,6-dimethyl-1,4-phenylene oxide) for application in fuel cells, J. Membr. Sci. 348 (2009) 167-173.

[22] M.L. Di Vona, E. Sgreccia, S. Licoccia, G. Alberti, L. Tortet, P. Knauth, Analysis of temperature-promoted and solvent-assisted cross-linking in sulfonated poly(ether ether ketone) (SPEEK) proton-conducting membranes, J. Phys. Chem. B 113 (2009) 7505-7512.

[23] A. Dyck, D. Fritsch, S.P. Nunes, Proton-conductive membranes of sulfonated polyphenylsulfone, J. Appl. Polym. Sci. 86 (2002) 2820-2827.

[24] C. Hartmann-Thompson, A. Merrington, P.I. Carver, D.L. Keeley, J.L. Rousseau, D. Hucul, K.J. Bruza, L.S. Thomas, S.E. Keinath, R.M. Nowak, D.M. Katona, P.R Santurri, Proton-conducting polyhedral oligosilsesquioxane nanoadditives for sulfonated polyphenylsulfone hydrogen fuel cell proton exchange membranes, J. Appl. Polym. Sci. 110 (2008) 958-974.

[25] L.E. Karlsson, P. Jannasch, Polysulfone ionomers for proton-conducting fuel cell membranes. 2. Sulfophenylated polysulfones and polyphenylsulfones, Electrochim. Acta 50 (2005) 1939-1946.

[26] B. Lafitte, P. Jannasch, Phosphonation of polysulfones via lithiation and reaction with chlorophosphonic acid esters, J. Polym. Sci. Part A-Polym. Chem. 43 (2005) 273-286.

[27] E. Parcero, F.J. Fernandez-Carretero, V. Compan, R. Herrera, L.F. del Castillo, E. Rianded, Electrochemical properties of cation-exchange membranes based on polysulfones, J. Electrochem. Soc. 155 (2008) F245-F252.

[28] E. Parcero, R. Herrera, S.P. Nunes, Phosphonated and sulfonated polyphenylsulfone membranes for fuel cell application, J. Membr. Sci. 285 (2006) 206-213.

[29] J. Pozuelo, F.J. Fernandez-Carretero, E. Riande, E. Saiz, V. Compan, Comparison between the conductivities of protons measured experimentally with the obtained by molecular dynamics simulations in sulfonated polyphenyl sulfones membranes, J. New Mater. Electrochem. Syst. 11 (2008) 87-94.

[30] H. Dai, R. Guan, C. Li, J. Liu, Development and characterization of sulfonated poly(ether sulfone) for proton exchange membrane materials, Solid State Ionics 178 (2007) 339-345.

[31] R. Nolte, K. Ledjeff, M. Bauer, R. Mulhaupt, Partially sulfonated poly(arylene ether sulfone) - a versatile proton conducting membrane material for modern energy-conversion technologies, J. Membr. Sci. 83 (1993) 211-220.

[32] M.L. Di Vona, L. Luchetti, G.P. Spera, E. Sgreccia, P. Knauth, Synthetic strategies for the preparation of proton-conducting hybrid polymers based on PEEK and PPSU for PEM fuel cells, C.R. Chim. 11 (2008) 1074-1081.

[33] M.L. Di Vona, S. Licoccia, P. Knauth, Organic-inorganic hybrid membranes based on sulfonated polyaryl-ether-ketones: correlation between water uptake and electrical conductivity, Solid State Ionics 179 (2008) 1161-1165.

[34] D.P. Lu, H. Zou, R. Guan, H. Dai, L. Lu, Sulfonation of polyethersulfone by chlorosulfonic acid, Polym. Bull. 54 (2005) 21-28.

[35] R. Guan, H. Zou, D.P. Lu, C.L. Gong, Y.F. Liu, Polyethersulfone sulfonated by chlorosulfonic acid and its membrane characteristics, Eur. Polym. J. 41 (2005) 1554-1560.

[36] J.B. Rose, Sulphonated polyaryletherketones US Patent 4268650, 1981.

[37] E. Sgreccia, M.L. Di Vona, S. Licoccia, M. Sganappa, M. Casciola, J.F. Chailan, P. Knauth, Self-assembled nanocomposite organic-inorganic proton conducting sulfonated poly-ether-ether-ketone (SPEEK)-based membranes: optimized mechanical, thermal and electrical properties, J. Power Sources 192 (2009) 353-359.

[38] G. Alberti, R. Narducci, M. Sganappa, Effects of hydrothermal/thermal treatments on the water-uptake of Nafion membranes and relations with changes of conformation, counter-elastic force and tensile modulus of the matrix, J. Power Sources 178 (2008) 575-583.

[39] L. Bellamy, The Infrared Spectra of Complex Molecules, vol. 1, Chapman and Hall, London, 1980.

[40] Q. Li, R. He, J.O. Jensen, N.J. Bjerrum, Approaches and recent development of polymer electrolyte membranes for fuel cells operating above $100^{\circ} \mathrm{C}$, Chem. Mater. 15 (2003) 4896.

[41] E. Sgreccia, J.-F. Chailan, M. Khadhraoui, M. Di Vona, P. Knauth, Mechanical properties of proton-conducting sulfonated aromatic polymer membranes: stress-strain tests and dynamical analysis, J. Power Sources (2009), doi:10.1016/j.jpowsour.2009.09.061.

[42] A. Collier, H.J. Wang, X.Z. Yuan, J.J. Zhang, D.P. Wilkinson, Degradation of polymer electrolyte membranes, Int. J. Hydrogen Energ. 31 (2006) 1838-1854. 